Old Dominion University

ODU Digital Commons

OEAS Faculty Publications

Ocean, Earth \& Atmospheric Sciences

2010

\title{
Causes of Tropical Atlantic Paleo-Salinity Variation During Periods of Reduced AMOC
}

Xiuquan Wan

Ping Chang

Matthew W. Schmidt

Old Dominion University, mwschmid@odu.edu

Follow this and additional works at: https://digitalcommons.odu.edu/oeas_fac_pubs

Part of the Geology Commons, Oceanography Commons, and the Paleontology Commons

\section{Repository Citation}

Wan, Xiuquan; Chang, Ping; and Schmidt, Matthew W., "Causes of Tropical Atlantic Paleo-Salinity Variation During Periods of Reduced AMOC" (2010). OEAS Faculty Publications. 213.

https://digitalcommons.odu.edu/oeas_fac_pubs/213

\section{Original Publication Citation}

Wan, X. Q. Chang, P., \& Schmidt, M. W. (2010). Causes of tropical Atlantic paleo-salinity variation during periods of reduced AMOC. Geophysical Research Letters, 37(4), L04603. doi:10.1029/2009g1042013 


\title{
Causes of tropical Atlantic paleo-salinity variation during periods of reduced AMOC
}

\author{
Xiuquan Wan, ${ }^{1}$ Ping Chang, ${ }^{1}$ and Matthew W. Schmidt ${ }^{1}$ \\ Received 2 December 2009; accepted 21 January 2010; published 24 February 2010.
}

[1] During periods of reduced Atlantic meridional overturning circulation (AMOC) associated with a freshening of northern North Atlantic surface water, paleo proxy records indicate a corresponding surface salinity increase over the entire tropical Atlantic. Although latitudinal-shifts in the mean position of the Atlantic Intertropical Convergence Zone (ITCZ) can explain certain features of the paleo salinity reconstructions, this mechanism does not offer an explanation for the reconstructed basin-wide paleo-salinity response to AMOC change. Here, we present new results from general circulation model simulations that suggest the sea surface salinity (SSS) increase in the tropical north Atlantic during periods of weakened AMOC is mainly controlled by the atmospheric response to the North Atlantic cooling, while the oceanic teleconnection contributes to increased SSS over the equatorial and south tropical Atlantic Ocean. Citation: Wan, X., P. Chang, and M. W. Schmidt (2010), Causes of tropical Atlantic paleo-salinity variation during periods of reduced AMOC, Geophys. Res. Lett., 37, L04603, doi:10.1029/2009GL042013.

\section{Introduction}

[2] Paleoceanographic proxy records provide evidence for wide-spread surface cooling over the Northern Hemisphere at times of reduced Atlantic meridional overturning circulation (AMOC). Although the collapse of AMOC is associated with a freshening of surface waters at the sites of deep water formation in the northern North Atlantic, proxy records suggest a corresponding sea surface salinity (SSS) increase in the entire western tropical/subtropical Atlantic [Schmidt et al., 2004, 2006; Weldeab et al., 2006; Carlson et al., 2008] (Figure 1). This basin-wide tropical/subtropical Atlantic SSS increase contrasts sharply to the dipole-like sea-surface temperature (SST) response in Tropical Atlantic resulting from a slowdown of the AMOC [e.g. Stouffer et al., 2006] and its mechanism is not well understood.

[3] Although north-south migrations of the Atlantic Intertropical Convergence Zone (ITCZ) in response to glacial boundary conditions [Peterson et al., 2000; Koutavas et al., 2002; Chiang et al., 2003] must have impacted regional SSS patterns in the past, it is difficult to explain the overall pattern of reconstructed SSS change associated with reduced AMOC based on this mechanism alone. For instance, the southward migration of Atlantic ITCZ associated with the North Atlantic cooling [Chiang et al., 2003] would lead to an increase in SSS over the western tropical north Atlantic

\footnotetext{
${ }^{1}$ Department of Oceanography, Texas A\&M University, College Station, Texas, USA.

Copyright 2010 by the American Geophysical Union. 0094-8276/10/2009GL042013\$05.00
}

and a decrease in the equatorial south Atlantic. Nevertheless, proxy SSS records indicate that elevated SSS values during periods of reduced AMOC extended into the western South Atlantic as well [Weldeab et al., 2006; Carlson et al., 2008]. Therefore, it seems that the proposed mechanism explains a certain feature of paleo salinity observations, but does not offer an explanation for the basin-wide salinity increase associated with reduced AMOC strength.

[4] Chang et al. [2008] articulated an oceanic pathway change mechanism that does explain an overall salinity increase in both the northern and southern Tropical Atlantic. According to this mechanism, the tropical Atlantic response to a rapid change in the AMOC consists of two stages. The first stage occurs within first 10 years (roughly) after the onset of the freshwater forcing and is dominated by Kelvin wave-like propagation that first occurs along the western boundary of the North Atlantic, then along the equator, and finally along the eastern boundaries of the basin. The second stage occurs when the AMOC is weakened beyond a threshold, takes longer to achieve and involves changes in the oceanic pathway. It is this latter process that we will demonstrate in this paper, through experiments with a coupled ocean-atmosphere model, is largely responsible for the elevated SSS values in the South Atlantic.

\section{Model Description and Numerical Experiments}

[5] The coupled ocean-atmosphere model used in this study consists of a tropical-channel ocean general circulation model based on the Geophysical Fluid Dynamics Laboratory's (GFDL) Modular Ocean Model version 3 (MOM3) [Pacanowski and Griffies, 1999] and the Community Climate Model version 3.6.6 (CCM3) - a global atmospheric general circulation model developed at the National Center for Atmosphere Research (NCAR) [Kiehl et al., 1998]. The configuration of MOM3 is the same as that described by Kirtman et al. [2002] except that the ocean model domain is confined between $30^{\circ} \mathrm{S}$ and $30^{\circ} \mathrm{N}$, including the Pacific, the Atlantic and the Indian Oceans. Open boundary conditions are employed at the northern and southern boundaries. The strength of the AMOC can be altered by specifying lateral open boundary conditions that are derived from simulations of global version of the MOM3. Before we apply the boundary conditions to the coupled model, we performed tropical-channel MOM3 simulations using boundary conditions derived from the global MOM3 control run with the same forcing as the global MOM3 runs. The result shows the tropical-channel MOM3 reproduces the AMOC of the global MOM3 in the tropics (not shown). Therefore, we are confident that the method of forcing is realistic. The CCM3 is coupled to the tropicalchannel MOM3 through an anomaly coupling methodology [Yeh et al., 2004]. Outside of the tropical ocean domain of 


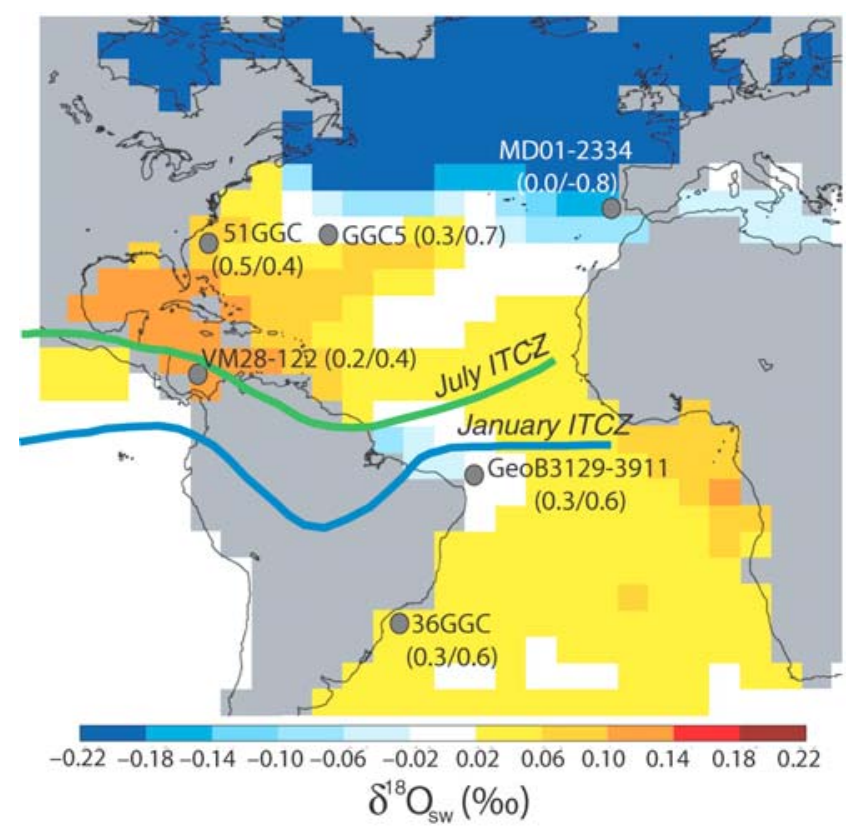

Figure 1. Modeled changes in surface $\delta^{18} \mathrm{O}_{\text {seawater }}$ resulting from a 50\% reduction in AMOC based on the coupled GCM NASA GISS ModelE-R [Schmidt et al., 2007]. Because the ${ }^{18} \mathrm{O} /{ }^{16} \mathrm{O}$ ratio of seawater covaries linearly with surface salinity, increases in $\delta^{18} \mathrm{O}_{\text {seawater }}$ indicate increased SSS. Also shown are the locations of proxy reconstructions (locations indicated in circles) indicating significant increases in surface $\delta^{18} \mathrm{O}_{\text {seawater }}$ during the Younger Dryas (first value) and for the Older Dryas (second value) for cores $51 \mathrm{GGC}, \mathrm{GGC} 5$, 36GGC [Carlson et al., 2008], VM28-122 [Schmidt et al., 2004] and GeoB3129-3911 [Weldeab et al., 2006]. The green (blue) line is the modern July (January) ITCZ location. Reprinted with permission of the Geological Society of America from Carlson et al. [2008].

$30^{\circ} \mathrm{S}$ and $30^{\circ} \mathrm{N}$, the CCM3 is forced by specified SSTs. Hereafter, we refer this model to as the CCM3-trMOM3 model. More detailed information about the model, including models' physical parameterizations, resolutions and performance in simulating major modes of variability can be found in the supplementary information of Wan et al. [2009].

[6] The CCM3-trMOM3 allows us to investigate separately the contributions of different physical processes asso- ciated with changes in the AMOC on salinity changes in the tropics. To do so, we conducted the following experiments:

[7] Control Experiment (CE): The atmospheric component of the CCM3-trMOM3 is forced with observed annual cycle of SST outside the tropical ocean domain and the oceanic component is forced with climatological inflow/ outflow conditions at the open boundaries derived from a global MOM3 simulation forced by observed climatological winds with restoring to observed climatological surface temperature and surface salinity. This run provides a baseline for other perturbation experiments.

[8] Boundary-Forcing Experiment (BFE): Same as CE except that the inflow/outflow conditions at the open boundaries are derived from a 100-year global MOM3 simulation with a fresh-water input at a rate of $1.0 \mathrm{~Sv}$ over northern North Atlantic $\left(63^{\circ} \mathrm{W} \sim 4^{\circ} \mathrm{E}, 55^{\circ} \mathrm{N} \sim 65^{\circ} \mathrm{N}\right)$, in addition to the observed climatological surface forcing. In the global MOM3 simulation the maximum AMOC rapidly weakens from $24 \mathrm{~Sv}$ to about $5 \mathrm{~Sv}$ after 10 years and reaches an equilibrium state through the rest of simulation [Wan, 2009]. This run is designed to examine the effect of ocean circulation changes on tropical salinity without changes in the atmospheric forcing.

[9] Surface-Forcing Experiment (SFE): Same as CE except that a cold SST anomaly derived from an ensemble of GFDL fully coupled climate model (GFDL CM2.1) water hosing runs [Zhang, 2007] are superimposed onto the observed SST climatology to force the atmosphere in the North Atlantic basin (north of $20^{\circ} \mathrm{N}$ ), to examine the effect of atmospheric processes over the Atlantic basin on tropical SSS.

[10] Combined-Forcing Experiment (CFE): This run combines the AMOC forcing in BFE and the North Atlantic surface cooling in SFE and is designed to examine the combined effect of the atmospheric and oceanic processes on tropical salinity.

[11] All the experiments consist of 100-year integrations. The analyses presented below are based on averages of the last 60 years of the simulations.

\section{Analyses and Results}

[12] We begin our analysis by first examining how tropical Atlantic salt budget changes in response to AMOC changes. Figure 2 shows the salt transport as a function of latitudes for $\mathrm{CE}$ and $\mathrm{CFE}$ experiments. For $\mathrm{CE}$ experiment, the tropical Atlantic Ocean $\left(20^{\circ} \mathrm{S}-20^{\circ} \mathrm{N}\right)$ exports salt to the

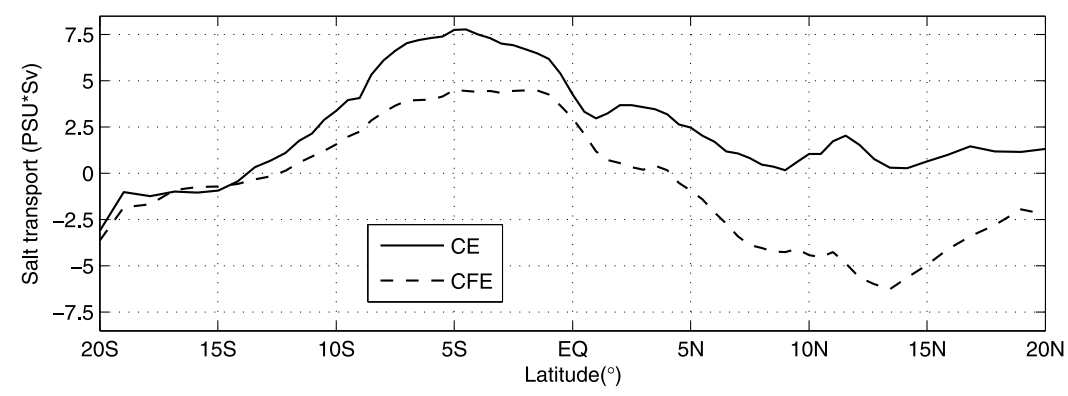

Figure 2. Salt transport, $\iint_{S v} d x d z$, where the integration was carried out for entire water column in depth and across the Atlantic basin in longitude, as a function of latitudes for CE and CFE experiments, based on the last 60-year of the simulations. 

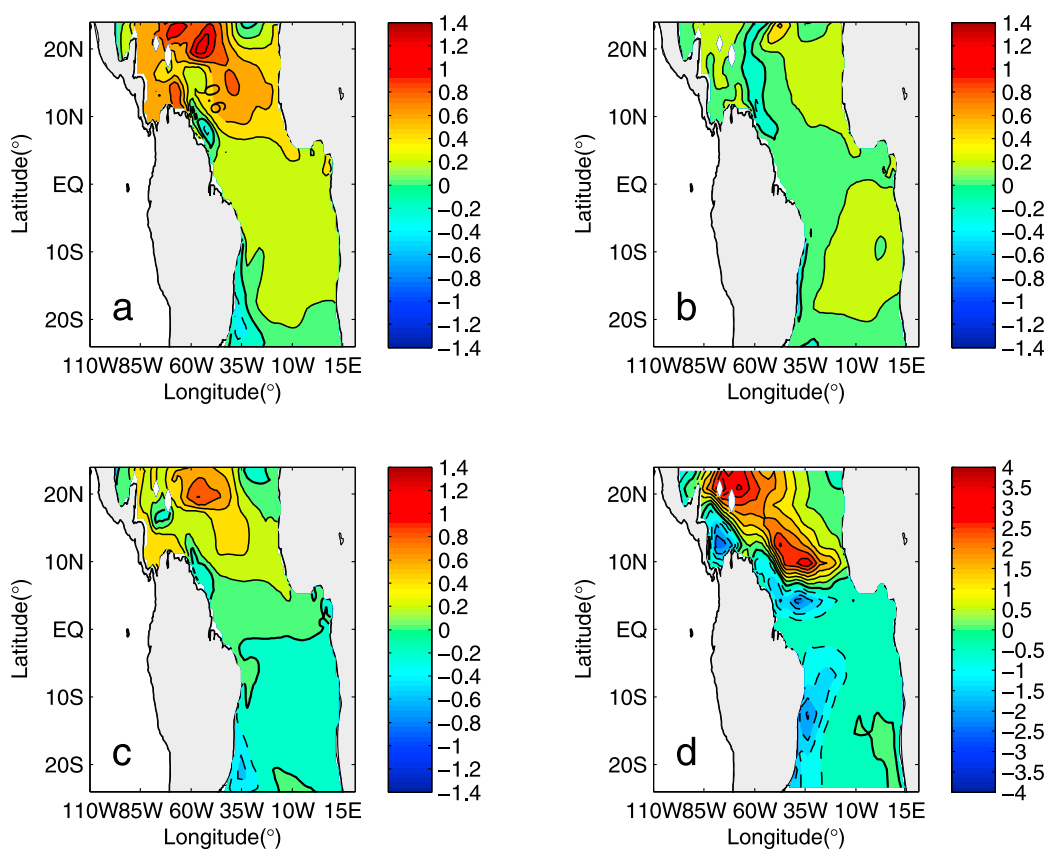

Figure 3. CCM3-trMOM3 simulated tropical surface salinity differences between (a) CFE and CE, (b) BFE and CE, (c) SFE and CE, respectively, and tropical precipitation difference between (d) CFE and CE, using the last 60-year data. Experiment details are given in the text. The interval of contour line is 0.2 for salinity and $0.5 \mathrm{~mm} / \mathrm{day}$ for precipitation. Red (blue) color means positive (negative) values, saline (freshening) water for salinity and dry (wet) for precipitation.

extratropics. To balance the fresh water budget, there must be a positive "salt flux" into the ocean at the surface through excessive evaporation over precipitation, i.e., $(\mathrm{E}-\mathrm{P})>0$, in the tropical domain. This balance changes drastically in CFE experiment where the AMOC is reduced. As shown in Figure 2, the salt transport in CFE changes sign from positive to negative in the north tropical Atlantic, indicating that the north tropical Atlantic, instead of exporting salt, is now importing salt from the north Atlantic. The maximum salt transport change occurs between $10^{\circ} \mathrm{N}-15^{\circ} \mathrm{N}$, which coincides with the region of oceanic pathway change [Chang et $a l ., 2008]$. This result hints that the large change in the salt transport is caused by ocean circulation changes. In contrast, the change of the salt transport in the south tropical Atlantic is much smaller, suggesting a weaker change due to ocean circulation. Although this salt budget analysis suggests that changes in the AMOC alter the salinity distribution in the tropical Atlantic, this analysis alone is not sufficient to elucidate SSS changes because the salt budget is balanced for the entire water column. To understand SSS changes, one needs to analyze the atmospheric and upper ocean processes that directly affect the ocean mixed layer.

[13] Figure 3a shows the simulated surface salinity changes in CFE experiment over the tropical Atlantic in reference to the control run. Consistent with proxy $\delta^{18} \mathrm{O}_{\text {seawater }}$ records for the tropical Atlantic (Figure 1) [Schmidt et al., 2004, 2006; Carlson et al., 2008; Weldeab et al., 2006], there is a basin-wide increase in SSS over the whole tropical Atlantic, although some differences exist with respect to magnitude and pattern of the salinity change. With the design of coupled model experiments, we show that the SSS change over tropical region associated with rapid AMOC decrease involves several physical processes, including changes in both the atmosphere and ocean.
[14] Figure 3d shows the corresponding model precipitation change between CFE and CE. Over the north subtropical region, we see consistency between the modeled SSS anomalies (Figure 3a) and the precipitation changes (Figure 3d), indicating that the surface freshwater flux is mainly responsible for the distribution of SSS anomalies in this region. Over the equatorial and south Atlantic, however, there is an increase in SSS in a region with elevated freshwater precipitation, suggesting that other mechanisms must be involved. We now demonstrate that the salinity increase in this region is caused by changes in oceanic pathway in response to the weakening of the AMOC.

[15] Figure 4a shows the AMOC in upper $500 \mathrm{~m}$, superimposed on zonally averaged salinity in CE. Two maximum salinity cores at $20^{\circ} \mathrm{S}$ and $20^{\circ} \mathrm{N}$ are clearly revealed. Of particular interest is the strong salinity gradient along $10^{\circ} \mathrm{N}$ separating the maximum salinity water of the north Atlantic subtropical gyre from the low salinity water of the tropical gyre. The zonally averaged salinity difference between CFE and $\mathrm{CE}, \mathrm{BFE}$ and CE, SFE and CE, are shown in Figures 4b, $4 \mathrm{c}$ and $4 \mathrm{~d}$, respectively. In BFE the AMOC weakens through changes in the open boundaries (Figure 4c), which causes the strength of the northward western boundary current (WBC) that carries the upper limb of AMOC cell to decrease. The anomalous advection of the reduced WBC acting on the strong salinity gradient near $10^{\circ} \mathrm{N}$ gives rise to a strong positive subsurface salinity anomaly (Figure 4c). Meanwhile, the subsurface branch of the northern Atlantic subtropical cell (STC) which carries subducted water equatorward but is normally blocked from getting into the Tropics by the northward AMOC return flow [Fratantoni et al., 2000; Hazeleger and Drijfhout, 2006] (Figure 4a) forms an important component of the WBC in BFE experiment, allowing the maximum salinity water access to the equatorial zone 

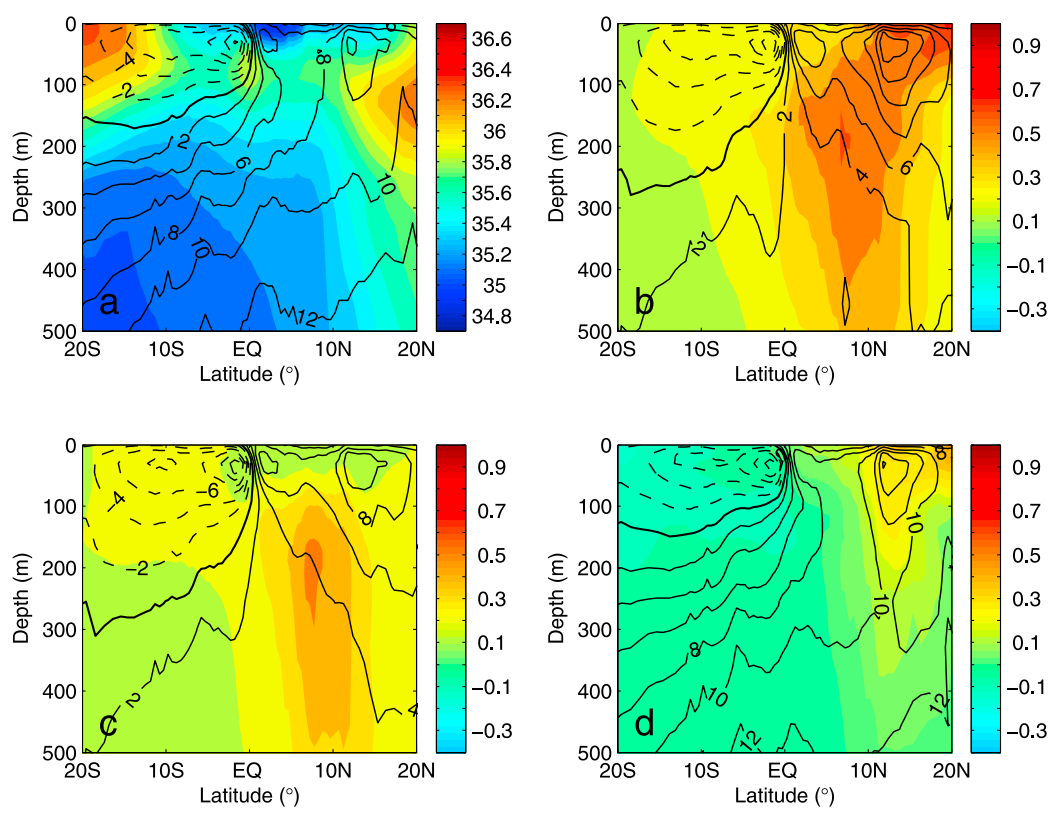

Figure 4. Upper Atlantic Ocean meridional overturning circulation streamfunction (contour) in (a) CE, (b) CFE, (c) BFE and (d) SFE, superimposed on zonally averaged salinity (color) in CE (Figure 4a), zonally averaged salinity difference (color) between CFE and CE (Figure 4b), BFE and CE (Figure 4c), SFE and CE (Figure 4d), respectively, using the last 60-year data. The color bars indicate the salinity (Figure 4a) and the salinity changes (Figures 4b, 4c, and 4d) and the streamfunction contour interval is $2 \mathrm{~Sv}$, where $1 \mathrm{~Sv}=10^{6} \mathrm{~m}^{3} \mathrm{~s}^{-1}$.

along the western boundary. This change in the oceanic pathway results in an increase in equatorial thermocline salinity, which eventually manifests itself as a surface salinity increase in the tropical Atlantic due to equatorial and coastal upwelling (Figure 3b). This is the same mechanism responsible for the surface warming over the equatorial south Atlantic ocean proposed by Chang et al. [2008].

[16] In contrast, if we only permit North Atlantic surface cooling to occur without changing ocean circulation, as in SFE, then surface salinity changes resemble the result of CFE in the north tropical Atlantic (Figures 3a and 3c), indicating that atmospheric processes dominate in these regions. In the equatorial south Atlantic, however, atmospheric processes cause a decrease in salinity (Figure 3d), contrary to the results of our CFE experiment (Figure 3a) and with paleoSSS reconstructions (Figure 1). Therefore, we conclude that oceanic circulation changes associated with AMOC variability play a critical role in driving salinity changes in the equatorial South Atlantic.

\section{Discussion}

[17] The coupled climate modeling results presented here provide a first look at how atmospheric and oceanic processes work together to produce a basin-wide increase of surface salinity in the tropical Atlantic that is consistent with reconstructed paleo-salinity change during periods of reduced AMOC, such as the Younger Dryas. We reason that the basin-wide increase of surface salinity in the tropical Atlantic could not be explained simply by the surface freshwater flux change associated with a southward shift of the ITCZ, as it would give rise to a dipole-like SSS anomaly with a high SSS in the North Tropical Atlantic and a low SSS in the South Tropical Atlantic. Therefore, the monopole SSS response may be attributed to the combined influence of atmospheric and oceanic processes. In the North Tropical Atlantic, the net surface freshwater flux change generated by atmospheric circulation change in response to the surface cooling in the North Atlantic dominates the SSS response. In the South Tropical Atlantic, enhanced rainfall associated with the southward immigration of the ITCZ decreases SSS, while the oceanic pathway change induced by the AMOC change acts to increase the SSS. The oceanic pathway mechanism allows salty subtropical gyre water to enter the equatorial south Atlantic region, causing a SSS increase in the region through upwelling. Our model experiments suggests that the oceanic process is more dominant and thus is responsible for the SSS increase in the South Tropical Atlantic.

[18] We emphasize that this study is a mechanistic exploration of dynamical processes contributing to paleo SSS change and is therefore not a full simulation of SSS response to past climate events. A full simulation requires the use of realistic paleo-climatic forcing and boundary conditions, which is beyond the scope of this study. Otto-Bliesner and Brady [2010] show that the overall response of upper tropical Atlantic temperature to AMOC variability in LGM hosing experiments remains similar to that of modern climate hosing experiments, in spite of a weakened AMOC by approximately $20 \%$ and a southward shifted north Atlantic subtropical gyre. However, whether the mechanisms presented here can fully explain paleo SSS changes requires further studies.

[19] An important finding of this study is that a careful model-data comparison of paleo SSS response in the tropical Atlantic may provide insight into the realism of freshwater forcing during periods of reduced AMOC. Future paleo modeling studies should not only focus on the SST response, but also pay attention to the SSS response to gain a full understanding of ocean and atmosphere processes in 
past abrupt climate changes. Since the surface process and the oceanic pathway mechanism are opposing each other in controlling SSS changes in the South Tropical Atlantic, the importance of ocean circulation changes is particularly noteworthy when SSS constraint is considered in past abrupt climate change studies.

[20] Acknowledgments. We thank two anonymous reviewers for their considered comments that helped to improve the manuscript. We also thank Rong Zhang for making GFDL CM2.1 freshwater-hosing experiment datasets available to us. The work was supported by the NSF grant OCE0623364 and DOE grant DEFG02-08ER64620.

\section{References}

Carlson, A. E., D. W. Oppo, R. E. Came, A. N. Legrande, L. D. Keigwin, and W. B. Curry (2008), Subtropical Atlantic salinity variability and Atlantic meridional circulation during the last deglaciation, Geology, 36, 991-994, doi:10.1130/G25080A.1.

Chang, P., R. Zhang, W. Hazeleger, C. Wen, X. Wan, L. Ji, R. J. Haarsma, W.-P. Breugem, and H. Seidel (2008), Oceanic link between abrupt changes in the North Atlantic Ocean and the African monsoon, Nat. Geosci., 1, 444-448, doi:10.1038/ngeo218.

Chiang, J. C. H., M. Biasutti, and D. S. Battisti (2003), Sensitivity of the Atlantic ITCZ to Last Glacial Maximum boundary conditions, Paleoceanography, 18(4), 1094, doi:10.1029/2003PA000916.

Fratantoni, D. M., W. E. Johns, T. L. Townsend, and H. E. Hurlburt (2000), Low-latitude circulation and mass transport pathways in a model of the tropical Atlantic Ocean, J. Phys. Oceanogr., 30, 1944-1966, doi:10.1175/1520-0485(2000)030<1944:LLCAMT>2.0.CO;2.

Hazeleger, W., and S. Drijfhout (2006), Subtropical cells and meridional overturning circulation pathways in the tropical Atlantic, J. Geophys. Res., 111, C03013, doi:10.1029/2005JC002942.

Kiehl, J. T., J. J. Hack, G. Bonan, B. A. Boville, D. Williamson, and P. Rasch (1998), The National Center for Atmospheric Research Community Climate Model: CCM3, J. Clim., 11, 1131-1149, doi:10.1175/15200442(1998)011<1131:TNCFAR $>2.0$. CO;2.

Kirtman, B. P., Y. Fan, and E. K. Schneider (2002), The COLA global coupled and anomaly coupled ocean-atmosphere GCM, J. Clim., 15, 23012320, doi:10.1175/1520-0442(2002)015<2301:TCGCAA>2.0.CO;2.

Koutavas, A., J. Lynch-Stieglitz, T. M. Marchitto Jr., and J. P. Sachs (2002), El Niño-like pattern in ice age tropical Pacific sea surface temperature, Science, 297, 226-230, doi:10.1126/science.1072376.
Otto-Bliesner, B. L., and E. C. Brady (2010), The sensitivity of the climate response to the magnitude and location of freshwater forcing: last glacial maximum experiments, Quat. Sci. Rev., 29, 56-73, doi:10.1016/j. quascirev.2009.07.004.

Pacanowski, R. C., and S. M. Griffies (1999), MOM 3.0 Manual, 668 pp., Geophys. Fluid Dyn. Lab., Natl. Oceanic and Atmos. Admin., Princeton, N. J.

Peterson, L. C., G. H. Haug, K. A. Hughen, and U. Röhl (2000), Rapid changes in the hydrological cycle of the tropical Atlantic during the last glacial, Science, 290, 1947-1951, doi:10.1126/science.290.5498.1947.

Schmidt, G. A., A. N. LeGrande, and G. Hoffmann (2007), Water isotope expressions of intrinsic and forced variability in a coupled oceanatmosphere model, J. Geophys. Res., 112, D10103, doi:10.1029/ 2006JD007781.

Schmidt, M. W., H. J. Spero, and D. W. Lea (2004), Links between salinity variation in the Caribbean and north Atlantic thermohaline circulation, Nature, 428, 160-163, doi:10.1038/nature02346.

Schmidt, M. W., M. J. Vautravers, and H. J. Spero (2006), Rapid North Atlantic salinity oscillations across Dansgaard-Oeschger cycles, Nature, 443, 561-564, doi:10.1038/nature05121.

Stouffer, R., et al. (2006), Investigating the causes of the response of the thermohaline circulation to past and future climate change, J. Clim., 19, 1365-1387, doi:10.1175/JCLI3689.1.

Wan, X. (2009), Effect of Atlantic meridional overturning circulation changes on tropical coupled ocean-atmosphere system, dissertation, Texas A\&M Univ., College Station.

Wan, X., P. Chang, R. Saravanan, R. Zhang, and M. W. Schmidt (2009), On the interpretation of Caribbean paleotemperature reconstructions during the Younger Dryas, Geophys. Res. Lett., 36, L02701, doi:10.1029/ 2008 GL035805.

Weldeab, S., R. R. Schneider, and M. Köllinga (2006), Deglacial sea surface temperature and salinity increase in the western tropical Atlantic in synchrony with high latitude climate instabilities, Earth Planet. Sci. Lett., 241, 699-706, doi:10.1016/j.epsl.2005.11.012.

Yeh, S. W., J. G. Jhun, I. S. Kang, and B. P. Kirtman (2004), The decadal ENSO variability in a hybrid coupled model, J. Clim., 17, 1225-1238, doi:10.1175/1520-0442(2004)017<1225:TDEVIA >2.0.CO;2.

Zhang, R. (2007), Anticorrelated multidecadal variations between surface and subsurface tropical North Atlantic, Geophys. Res. Lett., 34, L12713, doi:10.1029/2007GL030225.

P. Chang, M. W. Schmidt, and X. Wan, Department of Oceanography, Texas A\&M University, College Station, TX 77843, USA. 